Document downloaded from:

http://hdl.handle.net/10251/80861

This paper must be cited as:

Desantes Fernández, JM.; García Oliver, JM.; Vera-Tudela-Fajardo, WM.; López Pintor, D.; Schneider, B.; Boulouchos, K. (2016). Study of ignition delay time and generalization of auto-ignition for PRFs in a RCEM by means of natural chemiluminescence. Energy Conversion and Management. 111:217-228. doi:10.1016/j.enconman.2015.12.052.

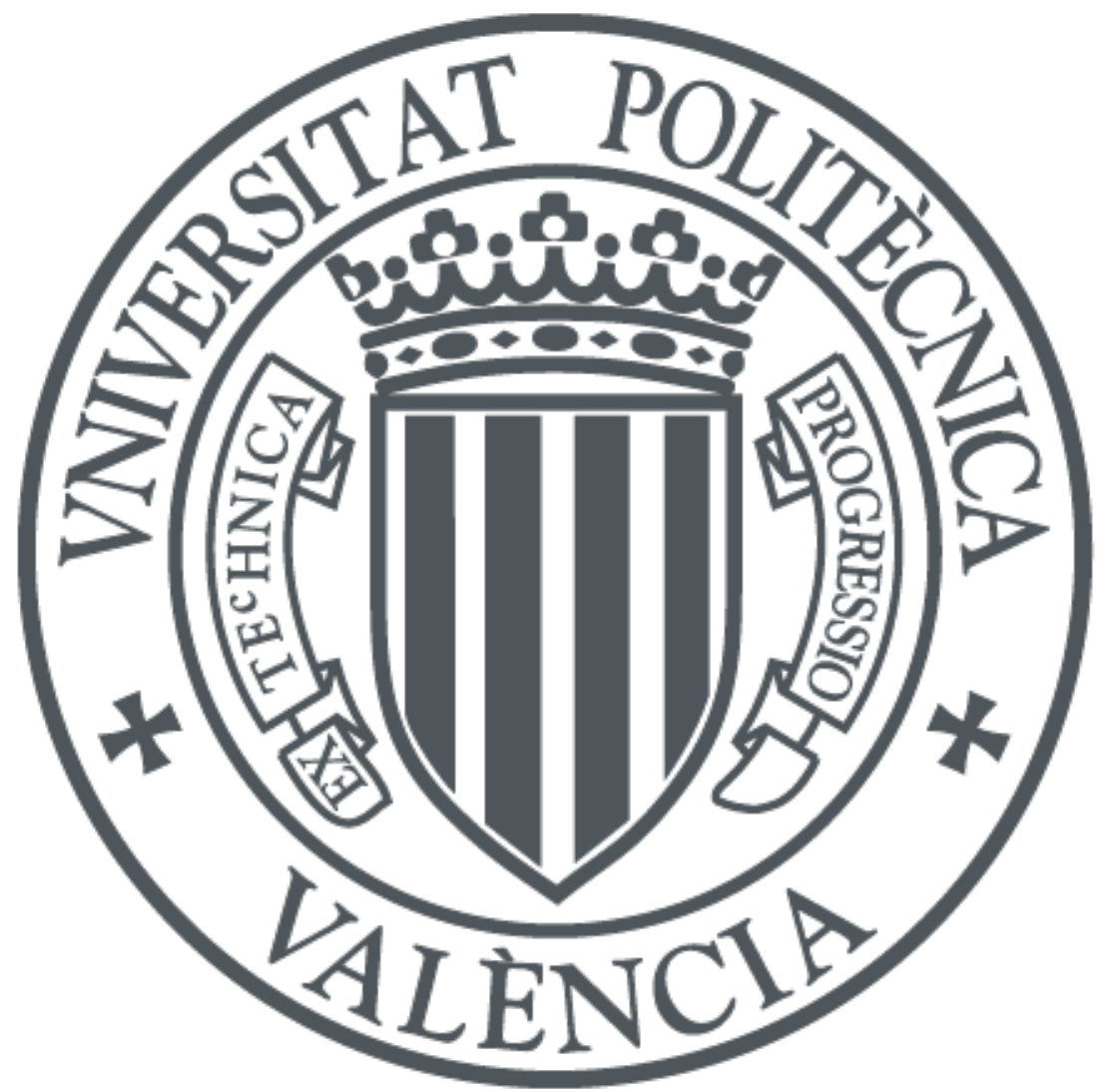

The final publication is available at

http://dx.doi.org/10.1016/j.enconman.2015.12.052

Copyright Elsevier

Additional Information 


\title{
Study of ignition delay time and generalization of auto-ignition for PRFs in a RCEM by means of natural chemiluminescence
}

\author{
J.M. Desantes ${ }^{\mathrm{a}}$, J.M. García-Oliver ${ }^{\mathrm{a}}$, W. Vera-Tudela, ${ }^{\mathrm{a}, \mathrm{b}, *}$, D. \\ López-Pintor $^{\mathrm{a}, \mathrm{b}, *}$, B. Schneider ${ }^{\mathrm{b}}$, K. Boulouchos ${ }^{\mathrm{b}}$ \\ ${ }^{a}$ CMT-Motores Térmicos \\ Universitat Politècnica de València \\ Camino de Vera, s/n. 46022 Valencia, SPAIN \\ ${ }^{b}$ Laboratorium für Aerothermochemie und Verbrennungssysteme \\ Eidgeössiche Technische Hochschule Zürich \\ Sonneggstrasse 3,CH-8092 Zürich, SWITZERLAND
}

\begin{abstract}
An investigation of the effects of contour conditions and fuel properties on ignition delay time under Homogeneous Charge Compression Ignition (HCCI) conditions is presented in this study. A parametric variation of initial temperature, intake pressure, compression ratio, oxygen concentration and equivalence ratio has been carried out for Primary Reference Fuels (PRFs) in a Rapid Compression Expansion Machine (RCEM) while applying the optical technique of natural chemiluminescence along with a photo-multiplier. Additionally, the ignition delay time has been calculated from the pressure rise rate and also corresponding numerical simulations with CHEMKIN have been done. The results show that the ignition delay times from the chemical kinetic mechanisms agree with the trends obtained from the experiments.
\end{abstract}

\footnotetext{
* Corresponding author

Tel: +34 963879 232. Fax: +34 963877 659. E-mail: walvetu@mot.upv.es dalopin1@mot.upv.es
} 
Moreover, the same mechanism proved to yield consistent results for both fuels at a wide range of conditions. On the other hand, the results from natural chemiluminescence also showed agreement with the ignition delay from the pressure signals. A $310 \mathrm{~nm}$ interference filter was used in order to detect the chemiluminescence of the $O H^{*}$ radical. In fact, the maximum area and peak intensity of the chemiluminescence measured during the combustion showed that the process of auto-ignition is generalized in the whole chamber. Moreover, the correlation of peak intensity, maximum area and ignition delay time demonstrated that natural chemiluminescence can also be used to calculate ignition delay times under different operating conditions. Finally, the area of chemiluminescence was proved to be more dependant on the fuel and ignition delay time than on the operating conditions.

Keywords: RCEM, ignition delay, $O H^{*}$ chemiluminescence, $\mathrm{PRF}$

\section{Introduction}

2 New combustion modes, such as Homogeneous Charge Compression Ignition (HCCI), Premixed Charge Compression Ignition (PCCI) and others 4 based on Low Temperature Combustion (LTC), have shown high potential for the simultaneous reduction of soot and $N O_{x}[1,2]$. These modes show virtually zero emissions of soot and $N O_{x}$, but high emissions of unburned hydrocarbons (UHC) and carbon monoxide $(\mathrm{CO})$, by avoiding the soot and \& $N O_{x}$ formation peninsulas, which can be seen in equivalence ratio - tem9 perature diagrams [3]. However, UHC and $C O$ can be easily oxidized with 10 the current post-treatment systems. Thus, the main challenge to implement 11 these new combustion strategies in commercial reciprocating internal com- 
bustion engines is the lack of control over the autoignition process and over the heat release rate [4].

The ignition control is much more difficult under these conditions because the autoignition is controlled by the chemical kinetics of the charge [5], which can be modified by adjusting the engine operating parameters, such as the Exhaust Gas Recirculation (EGR) rate and the inlet temperature. Therefore, it is necessary to improve the knowledge about the autoignition event and about the combustion process under low temperature conditions to properly modify the operating conditions of the engine and control the heat release.

Natural chemiluminescence is a non-intrusive optical technique widely used in combustion diagnosis [6], such optical techniques are powerful tools to analyze not only the ignition of homogeneous mixtures, but also different parameters of sprays and even exhaust emissions. Natural luminosity analysis and spectroscopy have shown to be able to describe the different phases of the combustion process under HCCI conditions [7].

Mancaruso and Vaglieco [8] performed chemiluminescence measurements in a transparent engine fuelled with RME and diesel commercial fuel. They found that $O H^{*}$ is responsible of the $N O$ formation in the chamber and, therefore, of much of the $N O_{x}$ emissions. The $O H^{*}$ behaviour in chamber was strictly correlated to formation-oxidation of $N O_{x}$-PM, demonstrating that $O H^{*}$ chemiluminescence can be used to study exhaust emissions.

Dubreuil et al. [9] studied the global effect of the EGR on the HCCI combustion of $n$-heptane in a transparent single-cylinder diesel engine for two EGR rates at a constant equivalence ratio by means of $O H^{*}$ chemiluminescence. By observing cool and main flame emissions, the authors found 
that the EGR delays and degrades the combustion phenomenon. They also proved that the natural emissions of combustion are sufficiently sensitive to yield combustion process analysis. Finally, the authors observed that the increase of the EGR rate decreases the $O H^{*}$ chemiluminescence, which is linked to the reduction of the global combustion reactivity.

Liu et al. [10] have used natural chemiluminescence to study the inhomogeneities present in HCCI combustion under different injection strategies and cooling fluid temperatures. Also, their results have been compared to CFD calculations.

Anders et al. [11] have performed studies in a truck size engine modified to have optical accesses and have applied chemiluminescence of $O H^{*}$ and $\mathrm{CH}$ to describe the combustion process. Results show that no luminosity is emitted during the NTC zone and that the radiation of the high temperature combustion is one order of magnitude larger than that of the cool flames.

Jin and Zheng [12] have elaborated a review where the description and literature revision of the diverse optical techniques applied to HCCI combustion can be found.

The motivation of this study is the analysis of the combustion under HCCI conditions in order to extend the aforementioned studies. The ignition delay behavior is now analysed under a wider range of conditions, extending the studies of Dubreuil et al. not only to other fuels, but also to different equivalence ratios, compression ratios and EGR rates. The importance of studying the ignition delay time under HCCI conditions is justified by the role of this parameter in controlling the heat release rate and the efficiency under such conditions. Additionally, it contributes to the HCCI knowledge 
using iso-octane which has similar ignition characteristics to gasoline. The optical study contributes by quantifying the homogeneity and propagation of the combustion and also by allowing the ignition delay time to be determined by chemiluminescence. Finally, a chemical kinetic mechanism for $n$-heptane and iso-octane blends is validated in a broad range of operating conditions. This will allow the use of the mechanism in future works of research.

In this study autoignition and combustion are studied under HCCI conditions in a Rapid Compression Expansion Machine (RCEM) by means of natural chemiluminescence. The study has been performed with two different surrogate fuels with reactivities typical of diesel fuel and gasoline: $n$-heptane and iso-octane, respectively. Despite the fact that more sophisticated surrogate fuels for diesel and gasoline can be found in the literature, $n$-heptane and iso-octane were chosen because extended and fully validated chemical kinetic mechanisms are available for both. Moreover, $n$-heptane, iso-octane and their blends are Primary Reference Fuels (PRF) employed to define the octane reference scale and they are widely used in the literature as surrogates of diesel and gasoline under engine conditions [13].

Ignition delay time and chemiluminescent intensity distribution will be experimentally obtained under different conditions of pressure, temperature, equivalence ratio and oxygen mass fraction. Experiments are reproduced with the software of chemical simulation CHEMKIN. This software, which is developed by Reaction Design (ANSYS), is consolidated in the world of engineering investigations and the chemical kinetics mechanisms of several hydrocarbons are perfectly defined to be used with it. Finally, the numerical results are validated experimentally using a RCEM. 
The structure of the paper is as follows: First, the experimental facilities involved in the study are presented. Then, the methodological approach is described, including the experimental methods, the chemical kinetic simulations and the parametric study performed. Afterwards, the trends of the ignition delay time are analyzed and the chemical kinetic mechanism is validated by comparison with experimental results. Next, the combustion process is studied from a point of view of natural chemiluminescence, comparing the experimental results with chemical simulations. Finally, the conclusions of this study are shown.

\section{Experimental tools}

\subsection{Rapid Compression Expansion Machine}

A RCEM is an experimental facility widely used in autoignition studies due to its capability to reproduce engine conditions [14]. It can replicate reasonably well the combustion process of reciprocating engines with fully controlled initial and boundary conditions while avoiding the complexities associated to engines [15].

Different compression ratios can be reached in the RCEM by varying the stroke and the clearance volume. Axial optical access is available [16] and the compression velocity can be varied in order to simulate the effect of different engine speeds. In a RCEM part of the expansion stroke of the piston can be also analyzed and most of the engine parameters can be calculated, such as the heat release rate or the combustion efficiency. In this facility both homogeneous and heterogeneous (direct injection) mixtures can be tested, as well as new combustion modes such as the dual fuel technology [17] or LTC 


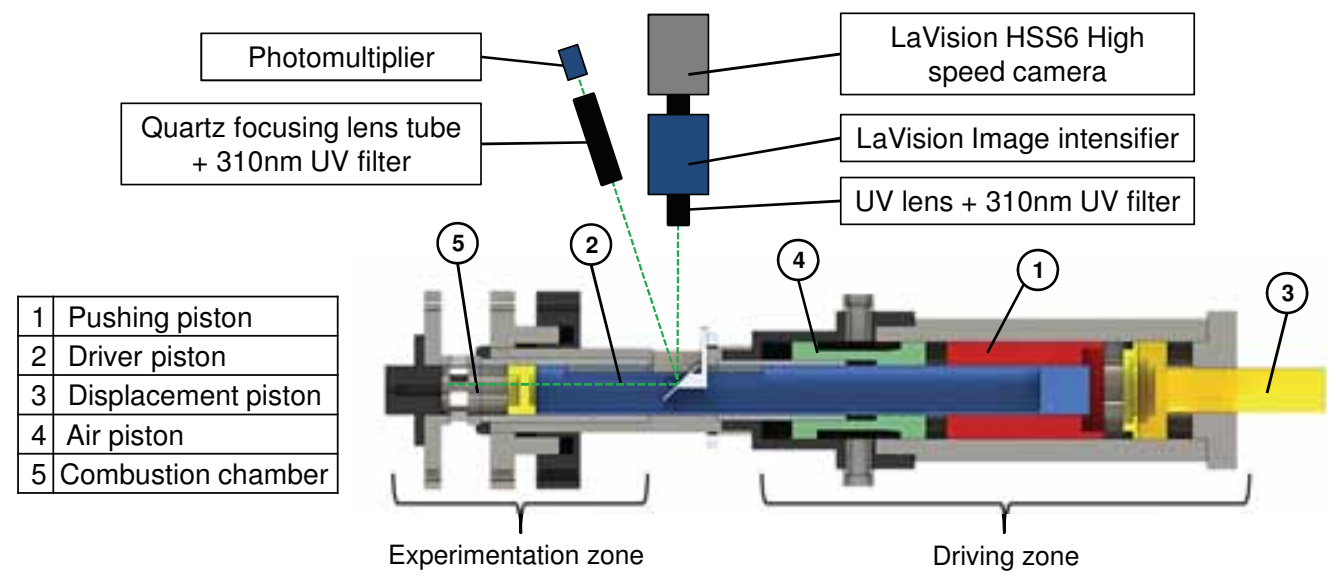

Figure 1: Rapid Compression Expansion Machine scheme.

[18].

A scheme of the RCEM is shown in Figure 1. The RCEM is pneumatically driven and its pistons are hydraulically coupled. As it can be seen, it can be divided in two different zones, the experimentation zone and the driving zone. The experimentation zone is composed by the combustion chamber, while the driving zone is composed by four different pistons. Piston 1, which is called pushing piston, is pneumatically driven and hydraulically coupled to piston 2, which is called driver piston and is directly connected with the combustion chamber. Piston 3 is hydraulically driven and it can be adjusted to select the compression stroke. Finally, piston 4 contains the compressed air that drives the machine.

The way in which the RCEM works is as follows: First, the oil is pressurized by the driving gas, which is compressed air. The driver piston does not move because it is perfectly coupled to piston 3 , avoiding contact between the pushing oil and the piston base. Then, pressure is established behind 
the driver piston by a bypass valve and it starts to advance at low velocity in a process called slow compression. It should be noted that when the driver piston advances, the pushing piston must advance also in the opposite direction, keeping constant the volume of oil. In fact, both pistons are inertially balanced, leading to a process free of vibrations. When the driver piston leaves the piston 3 , it is suddenly accelerated and the rapid compression stroke starts. The driving air suffers an expansion process whereby its pressure and, consequently, the pushing oil pressure, are reduced. The piston stops when the pressure in the combustion chamber is high enough to compensate the pushing force and the inertia, defining TDC. Thereby, TDC is highly dependent on the operation conditions of the RCEM, which is completely different for engines. Moreover, there is a certain maximum driving pressure for each operating condition to avoid collision of the piston with the cylinder head, since in the RCEM there is not any mechanism as the rod-crank mechanism that fixes the maximum position of the piston. Once the piston reaches TDC, the pressure in the combustion chamber is higher than the pushing oil pressure and the expansion stroke starts. More details on the operation principle of the RCEM can be found in [19].

The technical characteristics of the RCEM can be seen in Table 1. The pushing piston and the driver piston are instrumented with two AMO LMK102 incremental position sensors $(0.01 \mathrm{~mm}$ of resolution), which allow knowing the absolute position of each piston and, therefore, the combustion chamber volume. The combustion chamber is composed by three elements, the experimentation piston (mechanically connected to the driver piston), the liner and the cylinder head. The experimentation piston consists of a steel-made 


\begin{tabular}{|l|ll|}
\hline Bore & 84 & $\mathrm{~mm}$ \\
\hline Stroke & $120-249$ & $\mathrm{~mm}$ \\
\hline Compression ratio & $5-30$ & - \\
\hline Maximum cylinder pressure & 200 & $\mathrm{bar}$ \\
\hline Initial pressure & $1-5$ & bar \\
\hline Maximum heating temperature & 473 & $\mathrm{~K}$ \\
\hline
\end{tabular}

Table 1: Technical characteristics of the RCEM.

piston with $84 \mathrm{~mm}$ of bore and a quartz-made bowl with cylindrical shape, $50 \mathrm{~mm}$ of bore and $2.2 \mathrm{~mm}$ of depth, which allow the axial optical access. As the bowl is flat, the chamber can be recorded without any image distortion.

Besides, the cylinder head and the cylinder liner have different heating elements arranged in six separately controlled zones, which are responsible for heating the cylinder walls and the experimentation piston. The wall temperature is measured by a total of six K-type thermocouples, two located in the cylinder head and four in the liner. Very good temperature homogeneity has been observed [19], with a standard deviation of the gas temperature in the order of $3 K$. It was found that the distribution of temperature is barely affected by the gas in-flow due to its slow speed. An initial gas temperature equal to the wall temperature is achieved due to the long duration of the intake process.

The cylinder head is instrumented with a Kistler 7061B cooled piezoelectric pressure sensor $(-80 p C /$ bar of sensitivity), which is coupled to a Kistler 5011 charge amplifier, and whereby the in-cylinder pressure is mea- 
sured. Different piezo-resistive pressure sensors are available to control the filling of the driving gas and of the combustion chamber (0.01bar of resolution). The injection system is composed by a Siemens hollow cone piezoinjector with a cone angle of $90^{\circ}$, which is centered in the cylinder head. Its fuel delivery rate has been previously measured with an IAV injection rate analyzer. The transient signals have been recorded at $100 \mathrm{kHz}$ with a PCbased transient measurement recorder. The RCEM is filled from an external tank that can be heated up to $373 K$. The synthetic air is produced in the tank by a filling based on partial pressures where $\mathrm{N}_{2}, \mathrm{CO}_{2}$ and $\mathrm{O}_{2}$ can be used. The mixture is analyzed in a Horiba PG-250 portable gas analyzer in order to know the exact composition and ensure the correct reproduction of the experiments in CHEMKIN.

\subsection{Optical setup}

The area of autoignition and the luminous intensity were recorded by $O H^{*}$ chemiluminescence imaging. This technique records radiation at $310 \mathrm{~nm}$, which is controlled by the $O H^{*}$ radical, a marker of the high temperature combustion [20].

A schematic of the optical arrangement is shown in Figure 1. The camera has been pointed directly at the mirror inside the machine, which due to its $45^{\circ}$ tilt gives a direct view of the combustion chamber through the piston window. A 12-bit LaVision HighSpeedStar 6 camera coupled to a LaVision HighSpeed IRO intensifier equipped with a $100 \mathrm{~mm}$ focal length $f=2 \mathrm{UV}$ objective (by Bernhard Halle Nachfolger GmbH) were used for image acquisition; additionally, a 310 $\mathrm{nm}$ interference filter $(\mathrm{FWHM}=10 \mathrm{~nm})$ was used to eliminate any additional radiation outside the $O H^{*}$ radical wavelength. 
Because of the transient nature of the combustion, a acquisition frequency of $30 \mathrm{kHz}$ has been chosen in order to capture the evolution of the radical inside the combustion chamber. An exposure time of $33 \mu$ s and a rectangular image of $384 \times 448$ pixels allowed to see the whole effective window diameter of $50 \mathrm{~mm}$ while obtaining a pixel $/ \mathrm{mm}$ ratio of 6.89 . The maximum exposure time has been selected in order to use lower gain values and therefore reducing image noise.

Additionally, a Hamamatsu H5784-03 photo-multiplier (PHM), spectrally filtered at $310 \mathrm{~nm}$, captured the spatially integrated light emission through the piston window. It was placed at an angle due to the lack of space (Figure 1). The information from the photo-multiplier is complementary to the one obtained by the camera, as its higher dynamic range allows to see peaks in $O H^{*}$ luminosity when the camera might be saturating. On the other hand, the camera shows the distribution of the radical in a 2-dimensional image, while the photo-multiplier only returns an integrated value for the whole area.

The transient pressure, piston position and photo-multiplier signals along with control and synchronization signals (i.e. camera triggers) have been recorded at $100 \mathrm{kHz}$ with a $\mathrm{PC}$-based transient measurement recorder.

\section{Methodological approach}

\subsection{Rapid Compression Expansion Machine}

The desired stroke of the machine is selected and the RCEM is heated up to the desired temperature. Then, the synthetic air-EGR mixture is prepared in the mixing tank by a filling based on partial pressures. In this study, EGR 
was considered as a combination of $20 \% \mathrm{CO}_{2}+80 \% \mathrm{~N}_{2}$ in volume, and it is mixed with dry air until the amount of oxygen in the mixture is the one desired by the user.

The combustion chamber is scavenged several times before the filling. The fuel is injected into the combustion chamber at the start of the intake process to avoid problems of stratification or other inhomogeneities. The long duration of the process (approximately 40s), are enough to guarantee a homogeneous environment in the chamber when the compression stroke starts.

In order to ensure a representative ignition delay time measurement the number of repetitions of each point has been selected so that the semiamplitude of the confidence interval with a level of confidence of $95 \%$ is smaller than $1 \%$ of the mean ignition delay value.

In this work the autoignition of the mixture is considered to be produced when the time derivative of the pressure signal (which will be referred as pressure rise rate or, simply, pressure rise further on) reaches a maximum. Thus, the ignition delay in the experimental facility is defined as the time between the start of the rapid compression process and the instant in which the maximum pressure rise is obtained, as can be seen in Figure 2. This way, cool flames and high temperature ignition delay can be easily distinguished in case of two-stage ignition.

Finally, the temperature profile is calculated for each experiment by applying the energy equation, since the pressure profile and the position of the piston are known. The heat losses are characterized by a model based on the Woschni correlation [21]. The calculation includes two additional models for 


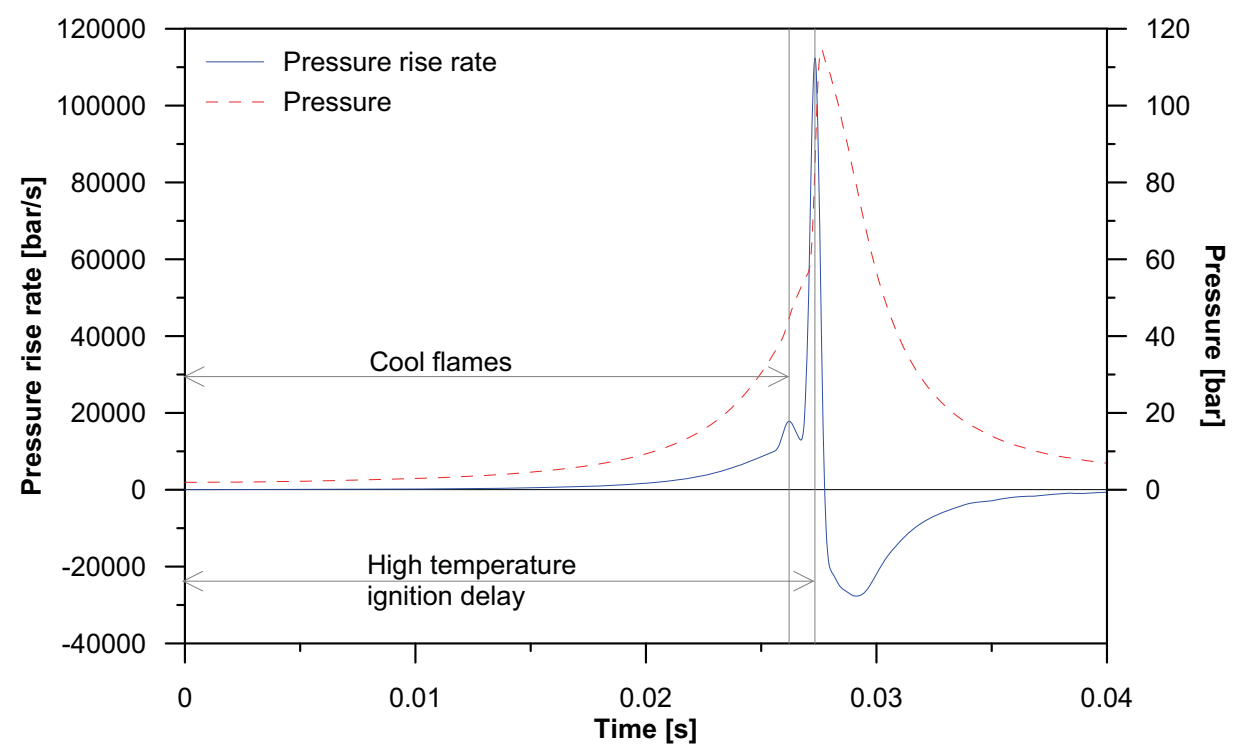

Figure 2: Ignition delay definition. The autoignition of the mixture is considered to be produced when the maximum pressure rise occurs. $n$-heptane at $C R 17, T_{i} 358 K$, EGR $47 \%$ and $\operatorname{Fr} 0.58$. 
deformations and leaks, both of them explained in $[22,23]$.

\section{2. $\mathrm{OH}^{*}$ chemiluminescence}

The images have been processed by an in-house developed routine in MATLAB. The processing algorithm starts by calculating the maximum pixel intensity of each frame in order to determine the useful dynamic range of the image sequence. Then, a background noise level is calculated by averaging 100 images where there is no presence of $O H^{*}$ luminosity; also, the maximum pixel intensity of all the images is determined. With this two values, the cutoff intensity is calculated using the probable error in order to select which frames are to be processed. A sample of the evolution of the pixel intensity, the background level and the selected points are shown in Figure 3.

The area of the natural chemiluminescence is determined by using two masks, one based on the window geometry and one on the luminosity. Figure 4-a shows a raw image straight from the camera, as it can be seen there is a wide range of intensity values inside the chamber as well as reflections outside the window. In order to discriminate the light reflected by the piston and cylinder walls, a geometrical mask with the diameter of the effective window is applied to all the images, leaving only the light that passes directly through the window to be processed; a sample of that mask is shown in Figure 4-b. Afterwards, a second mask based on the pixel intensity is applied. This mask is determined using the values of the maximum pixel and the background level previously calculated and a constant value to calculate a threshold. Therefore, all the values that fall below this threshold are considered to be part of the background, and the values above are accounted as $O H^{*}$ chemiluminescence; a sample of such mask is shown in Figure 4-c. Finally, 


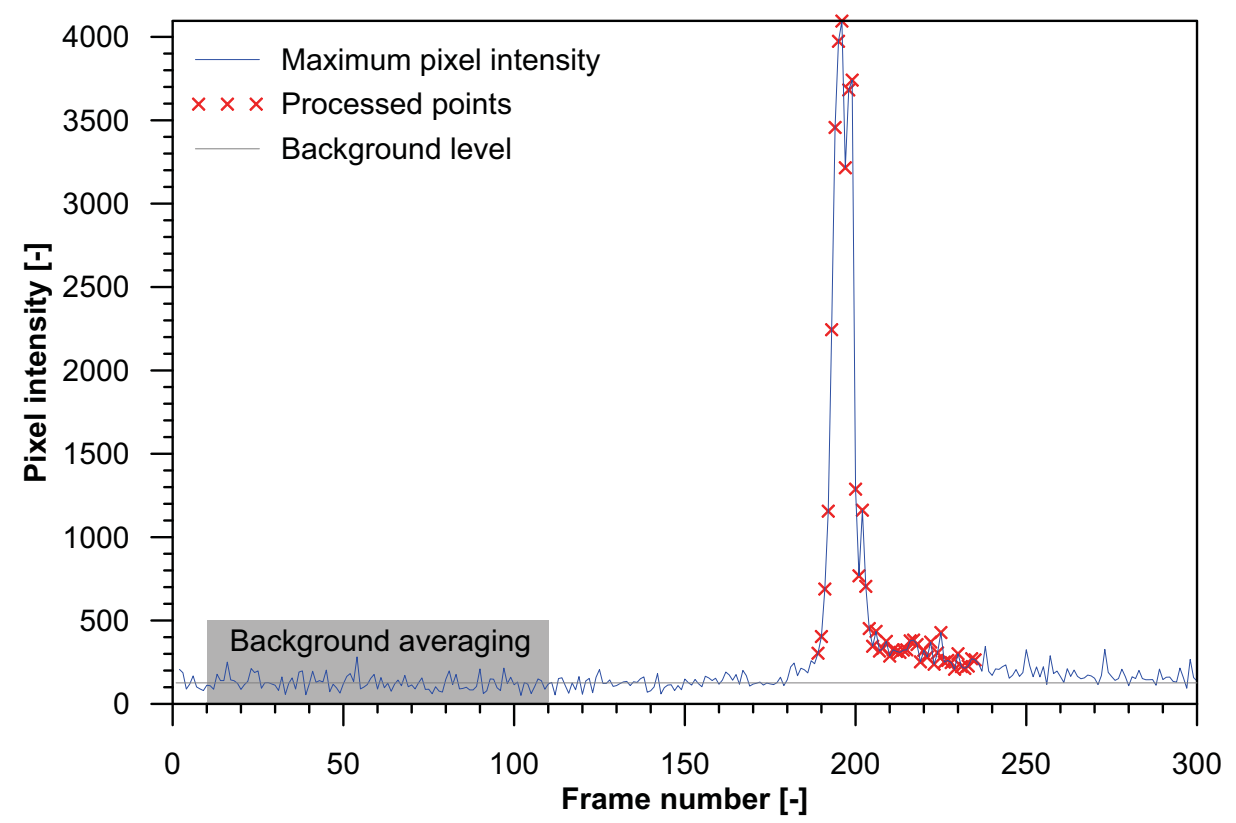

Figure 3: Evolution of maximum pixel intensity for frame sequence.

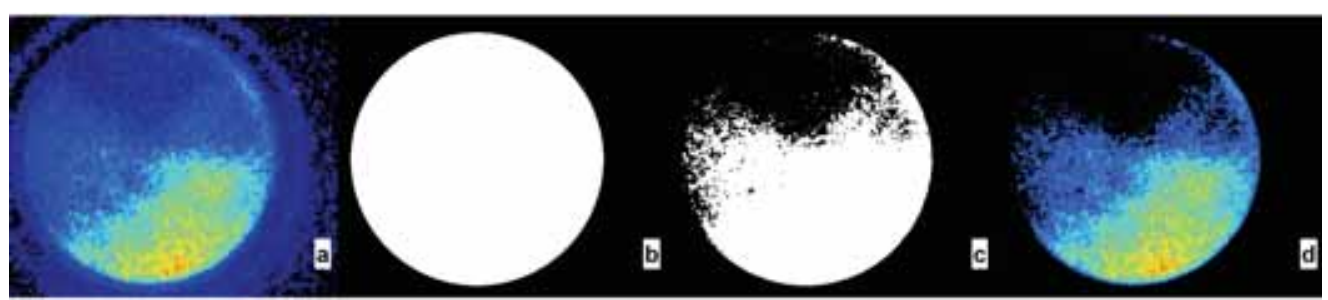

Figure 4: Processing sequence for raw image (a), geometrical mask (b), intensity mask (c) and final image $(\mathrm{d})$. 
the true intensity image excludes all the background light and the reflected light, as shown in Figure 4-d. Once the final image is obtained, the $O H^{*}$ area is calculated as a percentage of the full window and also the accumulated light intensity. Furthermore, since the images are time-resolved the instant at which the largest area and peak of intensity take place are also determined.

An important factor to keep in mind while applying two-dimensional imaging on a 3D phenomenon is the following. Since the light detected is an integrated value of the whole volume and not a single first plane acquisition, the maximum local intensity per volume may not be accurately detected by the optical techniques applied. The intensity gradients could have had an effect on the threshold of the images to obtain the combustion area, so a high-intensity single point could have been ignored. Nevertheless, since the combustion of homogeneous mixtures is being studied the existence of highintensity single points is very unlikely. Furthermore, for the calculation of the total combustion area this single non-detected point should represent a very small deviation.

\subsection{CHEMKIN and chemical kinetic mechanisms}

As previously mentioned, CHEMKIN is the software used to obtain the different ignition delays and critical concentrations. The version used is CHEMKIN-PRO. Curran's kinetic mechanism is used for $n$-heptane and iso-octane $[24,25]$. This mechanism consists of 1034 species and 4238 reactions, and includes the chemical kinetics of the two hydrocarbons used in this investigation. Its validity has been checked in several articles $[13,26]$ by comparison with experimental results.

The model used to obtain ignition delay times under variable conditions 
is a reciprocating internal combustion engine operating with homogeneous charge (IC-engine, closed 0-D reactors from CHEMKIN). The volume profile as well as the heat loss profile are imposed in order to reproduce the RCEM conditions. The piston starts at bottom dead center (BDC) and a complete cycle of the RCEM is simulated. The autoignition is considered to be produced when the time derivative of the pressure signal reaches a maximum. This is the same criterion as the used in the experiments and, therefore, it allows comparing the simulated results directly with the experimental ones. Moreover, the $\mathrm{OH}^{*}, \mathrm{CO}$ and $\mathrm{CO}_{2}$ concentration profiles are obtained and an analysis of their reaction rates has been performed in order to compare the simulations with the results obtained from the photo-multiplier and from the high speed camera. This way, the ignition delay referred to a maximum concentration can be directly compared with the ignition delay referred to natural chemiluminescence. The maximum time step for CHEMKIN simulations has been set as $10^{-5} s$ which is the experimental resolution of the pressure and photo-multiplier signals.

\subsection{Parametric study performed}

The performed experimental study was as follows:

- Fuel: n-heptane and iso-octane.

- Initial temperature $\left(T_{i}\right): 358 K$ (only for n-heptane), $383 K, 408 K$, $433 K$ and $458 K$.

- Initial pressure $\left(P_{i}\right): 0.14 M P a$ and $0.17 M P a$.

- Compression stroke: $249 \mathrm{~mm}$. 
- Compression ratio $(C R): 15$ and 17 .

- Oxygen mass fraction $\left(\mathrm{Y}_{\mathrm{O}_{2}}\right): 0.23$ (0\% EGR), 0.147 (30\% EGR), 0.126 (40\% EGR) and 0.105 (50\% EGR).

- Equivalence ratio $(F r)$ : from 0.3 to 0.8 depending on the fuel and on the oxygen mass fraction.

The maximum equivalence ratio is limited by the working oxygen mass fraction in order to avoid extremely violent combustions. The equivalence ratio of 0.4 has been chosen as base point in order to have the possibility to try leaner and richer mixtures without damaging the facility. The performed parametric study can be seen in Table 2. Finally, the temperature of the combustion chamber is always above the boiling point of the fuel, therefore ensuring that the fuel is in vapour phase before the beginning of the cycle.

\begin{tabular}{|c|c|c|c|c|c|c|}
\multicolumn{2}{c|}{} & $\mathbf{3 5 8}$ & $\mathbf{3 8 3}$ & $\mathbf{4 0 8}$ & $\mathbf{4 3 3}$ & $\mathbf{4 5 8}$ \\
\cline { 2 - 7 } \multicolumn{1}{c|}{} & $\mathbf{0 . 3}$ & 40 & & $0,30,40,50$ & & 40 \\
\hline $\mathbf{5}$ & $\mathbf{0 . 4}$ & $0,30,40,50$ & 40,50 & $0,30,40,50$ & 40,50 & $0,30,40,50$ \\
\cline { 2 - 7 } & $\mathbf{0 . 5}$ & 40 & 40 & 40,50 & 40 & 40 \\
\hline & $\mathbf{0 . 6}$ & 40 & & 40,50 & & 40 \\
\hline $\mathbf{0 . 7}$ & & & 40,50 & & \\
\hline $\mathbf{0 . 8}$ & & & 40,50 & & \\
\hline
\end{tabular}

Table 2: Parametric study performed. EGR percent for different initial temperatures and equivalence ratios. Blue.- exclusively for n-heptane. Red.- exclusively for iso-octane. 


\section{Results and discussion}

In this section, the trends of the ignition delay time, including the Negative Temperature Coefficient (NTC) behavior, are analyzed. This phenomenon is referred to the loss of reactivity when the temperature is increased due to the promotion of formation of olefins by the alkyl radicals, which competes with the formation of chain-carriers, retarding the ignition. Therefore, the ignition delay time increases when the temperature is increased in a certain range (NTC zone).

The validity of the chemical kinetic mechanism is checked by comparing them directly with the experimental results. Then, the combustion process is studied from a point of view of natural chemiluminescence. The generalization of the auto-ignition (percent of the combustion chamber ignited) is analyzed. Finally, the luminous intensity is studied, comparing the experimental results from the photo-multiplier and from the high speed camera with the chemical simulations.

4.1. Study of the ignition delay time and validation of the chemical mechanism

Ignition delay times obtained solving the $n$-heptane and iso-octane detailed chemical kinetic mechanism are compared with the experimental results as a method to validate the mechanism in the desired range.

As can be seen in Figure 5, simulations reproduce with high accuracy not only the trends, but also the values of the experimental results. Ignition delay is defined in both cases as the time between the start of the rapid compression process and the instant at which the maximum pressure rise 

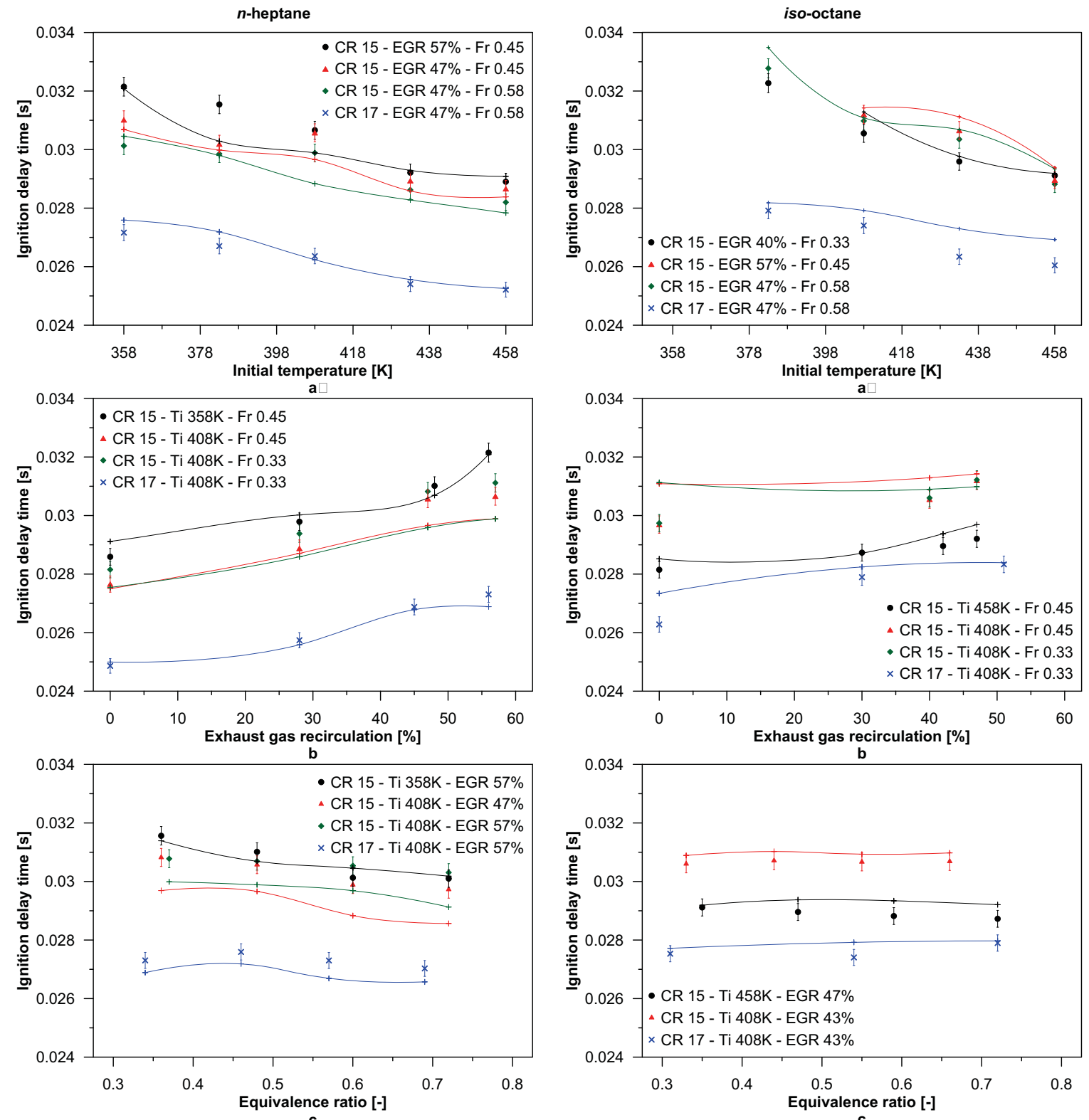

Figure 5: Ignition delay versus initial temperature (a), EGR rate (b) and equivalence ratio (c) for both fuels and under different operating conditions. Markers - RCEM, Lines - CHEMKIN. 
occurs.

As expected, the following trends in the ignition delay were experimentally observed (markers in Figure 5):

- Ignition delay decreases when the initial temperature is increased. For $n$-heptane, this is the case except in the negative temperature coefficient zone, NTC. In the parametric study performed, and if other parameters such as pressure, equivalence ratio and oxygen fraction are obviated, the ranges of the NTC zone are the following:

- iso-Octane: initial temperature between $408 K$ and $433 K$.

- $n$-Heptane: initial temperature between $383 K$ and $408 K$.

Moreover, it can be seen that the NTC zone becomes less pronounced if the pressure is increased. In the same way, it can be seen that the NTC behaviour becomes less evident if the EGR rate is increased in the explored range. This is caused because a higher EGR rate leads to lower temperatures, leading to an ignition outside the NTC zone. However, the NTC behaviour becomes clearer if the oxygen proportion is reduced at constant ignition temperature [27]. Besides, the NTC zone becomes less apparent if the equivalence ratio is increased. Finally and as expected, the NTC zone of the $n$-heptane is more distinct than the NTC zone of the iso-octane.

- Ignition delay decreases when the compression ratio is increased, since higher temperatures are reached in the cycle. 
- Ignition delay increases when the EGR rate is increased. Lower amount of oxidizer implies minor reactivity. Moreover, higher EGR rates implies higher amount of $\mathrm{CO}_{2}$, which implies higher heat capacity of the mixture and lower temperatures reached in the cycle.

- Ignition delay decreases when the equivalence ratio is increased in the explored range. Because the reaction paths at low temperatures are dependant on radical species formed directly from the fuel, the richer mixtures have lower ignition delays than the leaner ones. Whereas this trend is clear for $n$-heptane, the ignition delay seems to be much more independent of the equivalence ratio for iso-octane.

The percentage deviation in ignition delay $(\epsilon)$, was calculated in order to compare more easily experimental and simulation results. This deviation is defined as follows:

$$
\epsilon=\frac{t_{i, I C E}-t_{i, R C E M}}{t_{i, R C E M}} \times 100
$$

where $t_{i}$ represents the time of ignition (ignition delay under variable conditions). The subscript ICE represents a data obtained from a chemical simulation with CHEMKIN using a closed 0-D IC-engine reactor. Finally, the subscript $R C E M$ represents a data obtained experimentally from the RCEM.

The ignition delay deviation is shown in Figure 6 for all cases and both fuels. The results show that simulations are able to reproduce the experimental ignition delays with quite good accuracy. The average of the errors in absolute value, $\bar{\epsilon}=\sum|\epsilon| / n$, has been calculated for each fuel. In fact, the 


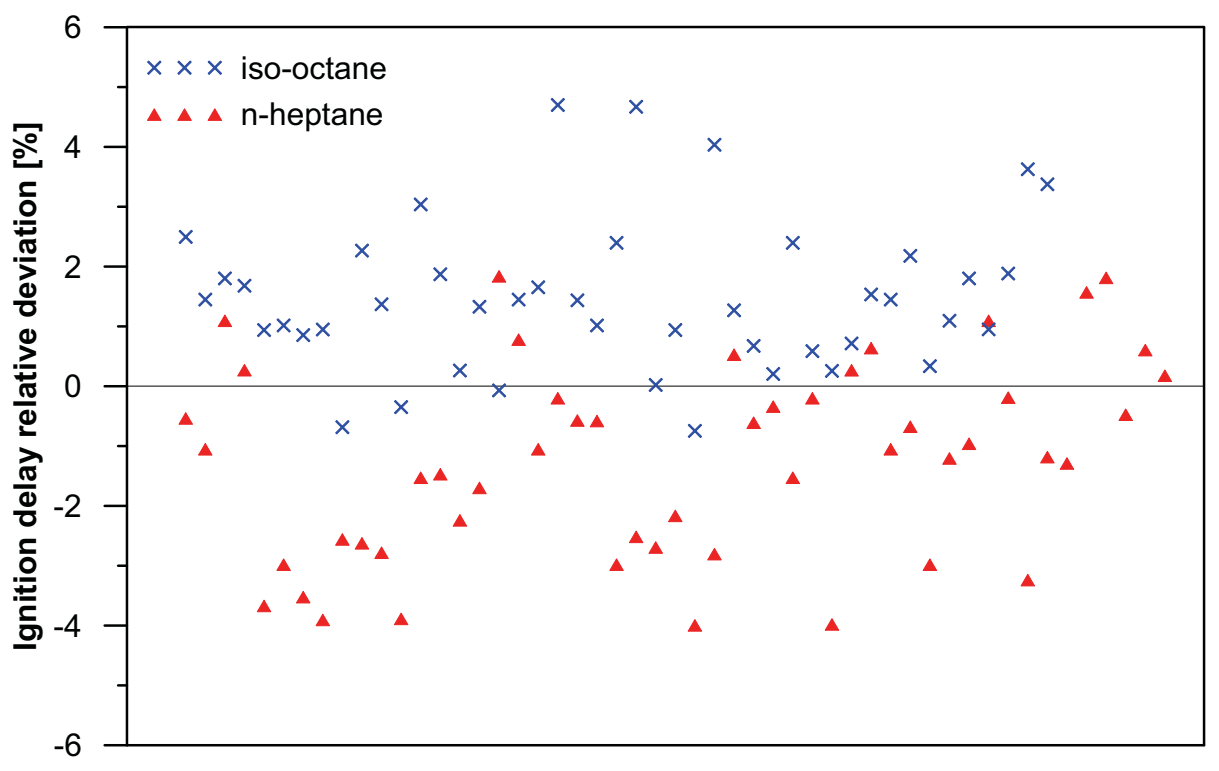

Figure 6: Percentage deviation in ignition delay.

confidence interval for the mean deviation with a confidence level of $95 \%$ is equal to $[1.33,1.98] \%$ for $n$-heptane and to $[1.21,1.89] \%$ for iso-octane. Ignition delay errors are caused partly by the chemical kinetic mechanism used and partly by the uncertainties in the calculation of the effective volume and the heat losses of the RCEM.

In Figure 6 the chemical kinetic mechanism under-predicts the ignition delay for $n$-heptane whereas it over-predicts the ignition delay times for isooctane. This fact is independent of the physical models used to characterize the heat losses and the deformations, since they are the same for both fuels. Moreover, the temperature is always high enough to keep the fuel in vapor phase, therefore these discrepancies are not due to a physical evapo- 
ration time. The chemical mechanism that was used has been designed from the detailed chemical kinetics of $n$-heptane [24] and iso-octane [25]. Moreover, the mechanism of iso-octane is based on that of $n$-heptane, where in order to reproduce the very low reactivity observed experimentally at low temperatures (600-770 $\mathrm{K}$ ) the rates of alkyl-peroxyl radical isomerization and peroxy-alkylhydroperoxyl radical isomerization have been decreased by a factor of three (relative to the $n$-heptane). The reason why the isomerization rates of $i s o$-octane are slower that those of $n$-heptane is not clear (other pathways could occur at low temperatures). The authors think that this reduction of isomerization rates is the cause why the mechanism underpredicts the ignition delay times for $n$-heptane, and over-predicts them for iso-octane.

\subsection{Generalization and intensity of the auto-ignition}

The radiation profiles are compared to the oxidation rates of $\mathrm{CO}$ to $\mathrm{CO}_{2}$ and also to the $O H^{*}$ concentration obtained from CHEMKIN (Figure 7). The radiation emitted at $310 \mathrm{~nm}$ could have two possible origins. On one hand it could be due to the natural chemiluminescence of the $O H^{*}$ radical, and on the other hand, it could also come from the $C O$ continuum (oxidation of $\mathrm{CO}$ to $\mathrm{CO}_{2}$ ).

The oxidation of $C O$ and the accumulation of $O H^{*}$ occur simultaneously. Therefore, a priori, it is not possible to decide without a spectrograph if the natural chemiluminescence at $310 \mathrm{~nm}$ belongs to $O H^{*}$ or if it is out-shined by the $C O$ continuum. However, it should be noted that the time of life of the luminous intensity is very different in case of belonging to $C O$ continuum or to $O H^{*}$, as can be seen in Figure 7, where the time of life of the $O H^{*}$ 

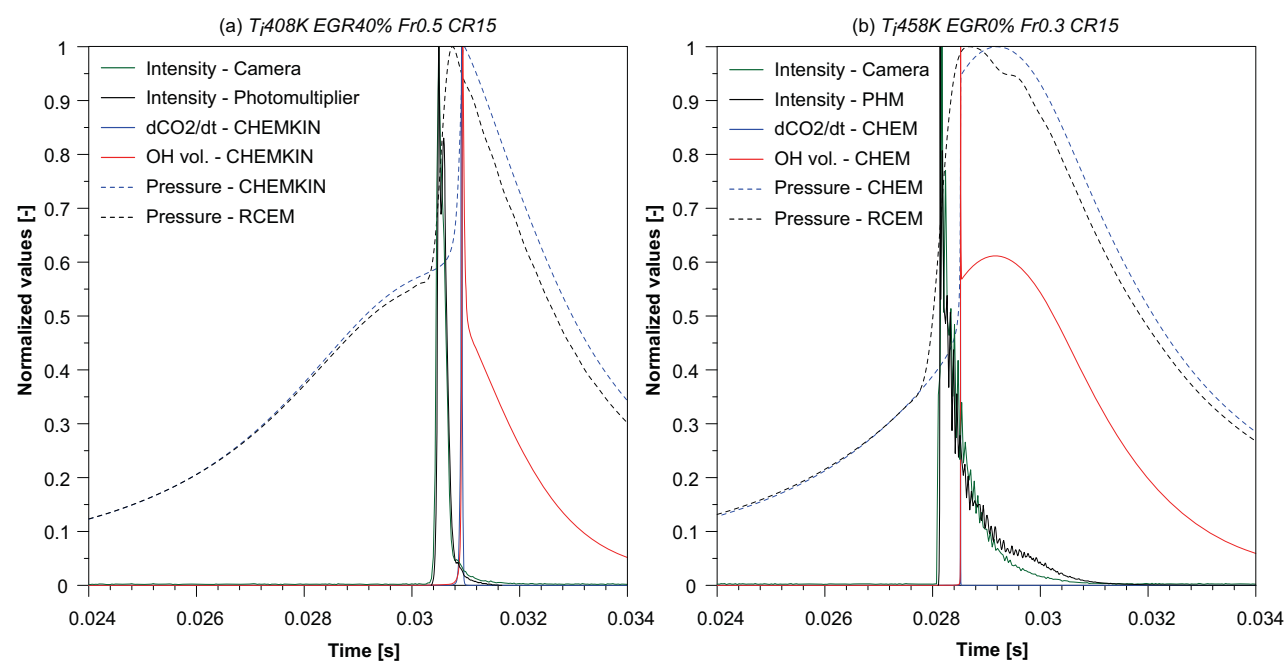

Figure 7: Normalized evolution of the oxidation rate of $\mathrm{CO}, O H^{*}$ molar fraction, natural chemiluminescence intensity from camera and photomultiplier, and simulated and experimental pressures for two different cases, based on chemiluminescence time of life. Left.Short time of life. Right.- Long time of life.

chemiluminescence is $0.65 \mathrm{~ms}$ longer than the $C O$ continuum luminosity. Thus, it is possible to use this parameter as a criterion to determine the source of the radiation.

Finally, from Figure 7 it can be seen that the profiles obtained from the photomultiplier and by integrating the luminosity detected by the camera are almost identical. This is a logical results as both detection methods are measuring the same parameter in parallel.

The generalization of the auto-ignition is defined as the percentage of the combustion chamber that has ignited; and since the auto-ignition is a transient event it can only be seen for a brief moment. Coincidentally the 


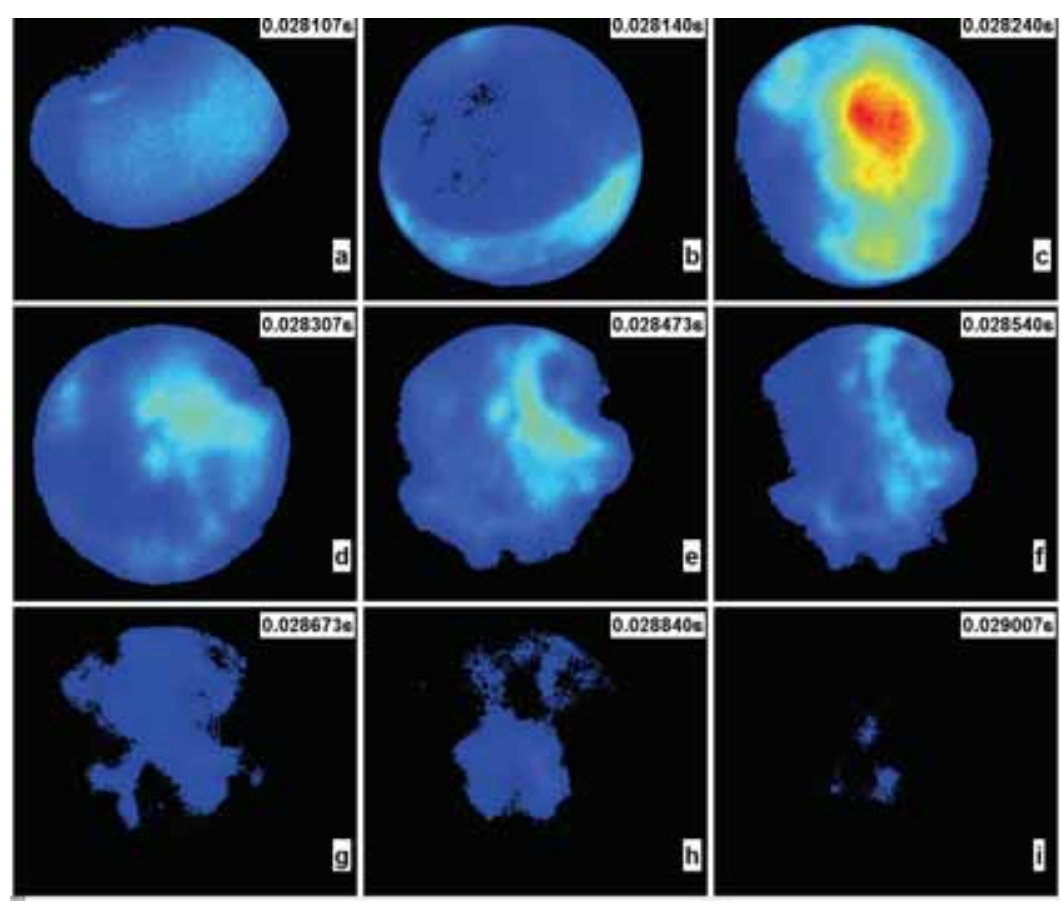

Figure 8: Evolution of chemiluminescence inside chamber for iso-octane at $C R 15, T_{i}$ $458 K$, EGR $0 \%$ and $\operatorname{Fr} 0.3$.

instant at which the largest area takes place is also the moment at which the radiation of the natural chemiluminescence is most intense. Moreover, both points also happen at the peak of the pressure rise curve; therefore, the mixture ignites abruptly causing a rise in the pressure while the radiation is maximum and present throughout the whole combustion chamber.

Figures 8 and 9 show two sequences of images where the evolution of the natural chemiluminescence over time can be seen in terms of intensity and area. Additionally, it can be seen that the ignition starts at the top of the combustion chamber, which occurred in most of the cases. This could be 


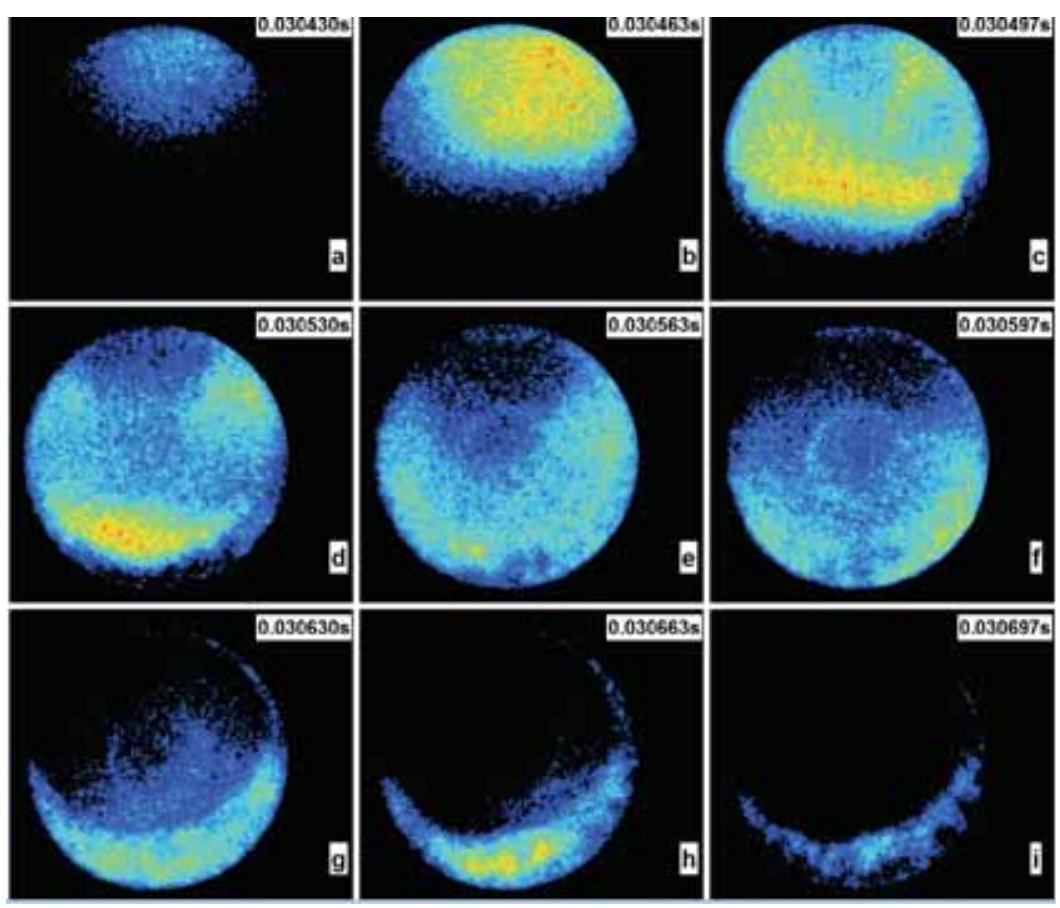

Figure 9: Evolution of chemiluminescence inside chamber for iso-octane at $C R 15, T_{i}$ 408K, EGR $40 \%$ and $\mathrm{Fr} 0.5$. 

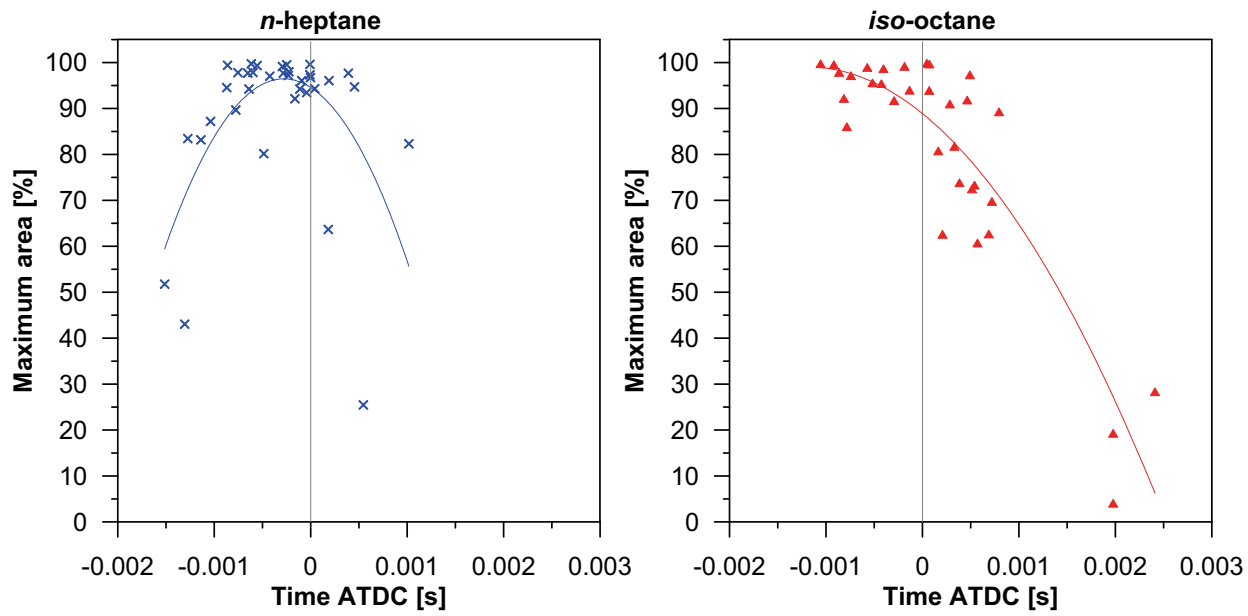

Figure 10: Maximum illuminated area versus time of largest area for both fuels at all conditions.

due to non-homogeneous temperature in the chamber walls; nevertheless, the ignition starts and is very quickly generalized, which is consistent with Figure 7. The luminosity is then exhausted first at the top, as the combustion began there and the last section of the window to show any chemiluminescence is, of course, at the bottom. The observed flame expansion velocity is too fast for a real flame front propagation, which supports the argument that it is an autoignition process.

As a final point of analysis using the area occupied by natural chemiluminescence, Figure 10 shows the evolution of the maximum area as a function of the instant after TDC at which the ignition takes place. The maximum area is highly dependant on the instant at which the ignition takes place, because if even though all the initial conditions are favourable for a full-area 
auto-ignition, if the ignition occurs far away of TDC, the thermodynamic conditions in the combustion chamber are not optimal for the propagation of the auto-ignition front, leading to slower ignitions and areas below $100 \%$. With this in mind, the trends presented in Figure 10 back up the hypotheses of area vs time relationship, as we can see that for $n$-heptane which has ignition delay times close to TDC most values are very high and close to $100 \%$ (Figure 10-left), and the values that either happen too soon or too late have much smaller areas. For iso-octane the trend is also similar, however the values are not. Since for this second fuel most ignition delay times happen after TDC, hence the fit points downwards instead of being balanced on the center (Figure 10-right).

The maximum luminous intensity is analyzed as an estimator of the combustion intensity. As can be seen in Figure 11, the maximum intensity has a potential behaviour with the maximum temperature reached in the cycle. Moreover, the luminous intensity is higher in case of $i s o$-octane for the same temperature. Figure 12 shows the trends of the combustion intensity with the initial temperature (a), the EGR rate (b) and the equivalence ratio (c) for both fuels and under different operating conditions. As expected, the higher the initial temperature, the lower the EGR rate or the higher the equivalence ratio, the higher the maximum $O H^{*}$ luminous intensity. However, a higher reactivity of the mixture does not imply a higher combustion intensity (changes of trend in Figure 12). If ignition occurs far away of TDC, the maximum thermodynamic conditions reached can be lower than the ones obtained with a less reactive mixture that ignites near TDC, leading to lower luminous intensity. 


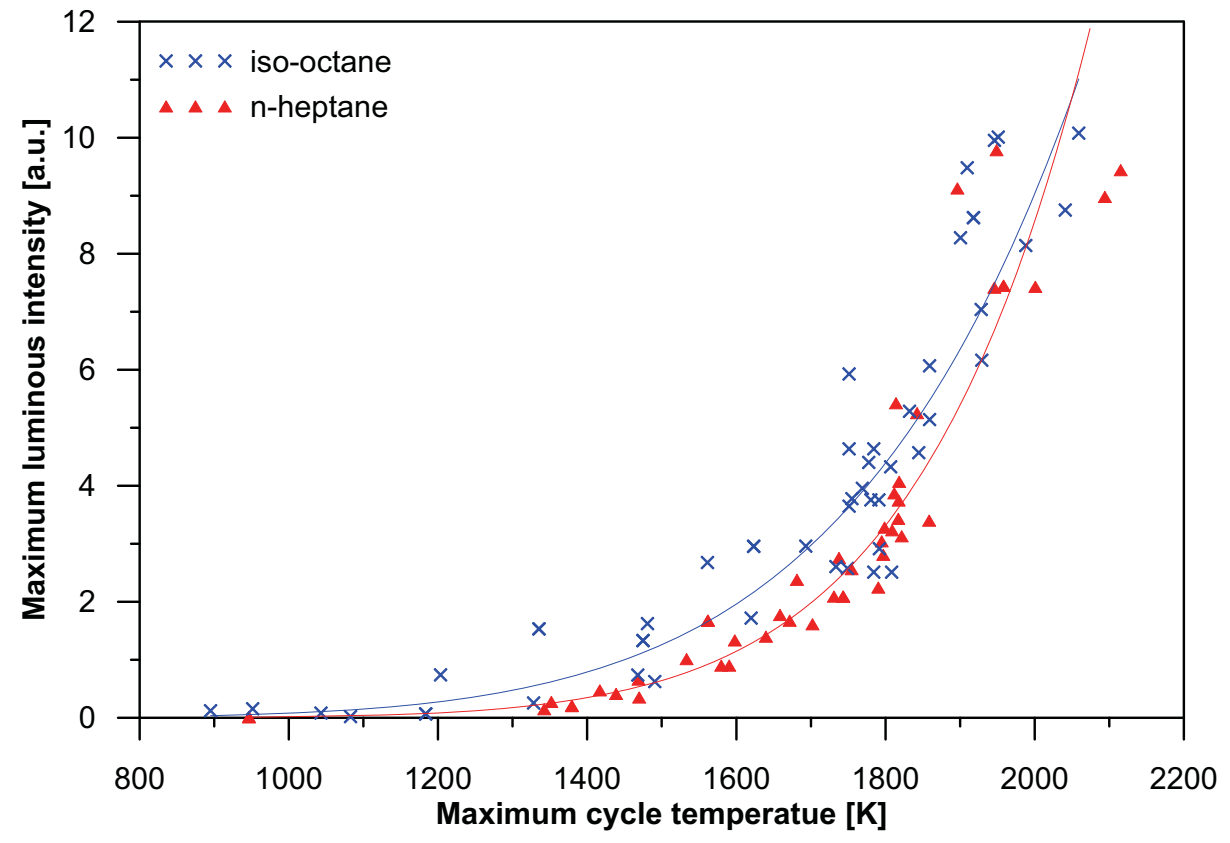

Figure 11: Maximum luminous intensity from the photo-multiplier versus maximum temperature reached in the cycle. 

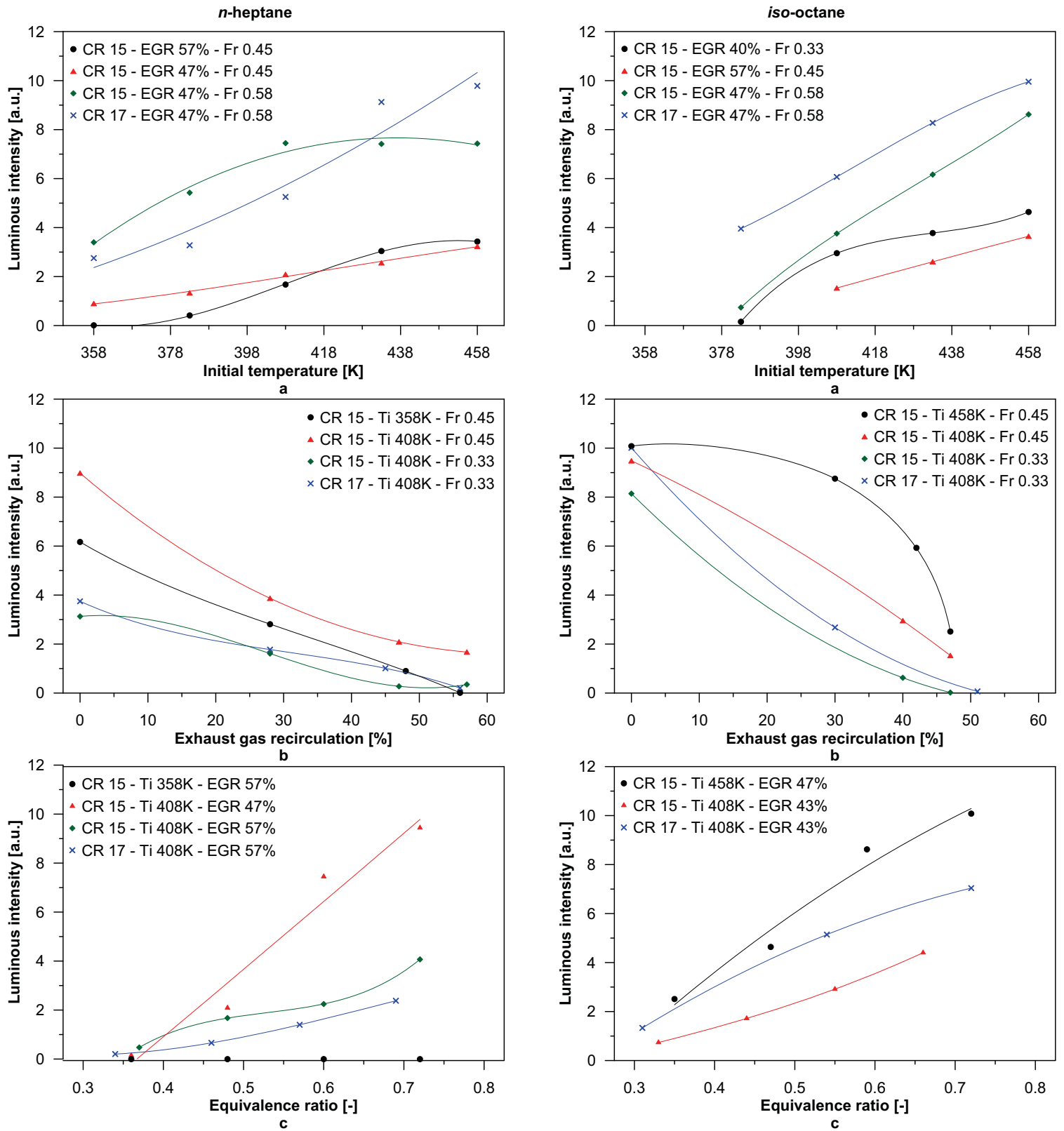

Figure 12: Maximum luminous intensity from the photo-multiplier versus initial temperature (a), EGR rate (b) and equivalence ratio (c) for both fuels and under different operating conditions. Markers - Experiments 31 Lines - Trends. 


\subsection{Comparison between experimental and simulated results}

An additional ignition delay time is defined referred to a maximum luminous intensity. This ignition delay is obtained experimentally from the photo-multipliers and from the high speed camera and by simulation from CHEMKIN. Despite the fact that the luminous intensity could proceed from two different sources, $O H^{*}$ or the $C O$ continuum, the maximum radiation emitted by both occurs at the same instant. The percentage deviation in the ignition delay $(\varepsilon)$, was calculated in order to compare more easily experimental and simulation results. This deviation is defined as follows:

$$
\varepsilon=\frac{t_{i l, I C E}-t_{i l, x}}{t_{i l, x}} \times 100
$$

where $t_{i l}$ represents the ignition delay time referred to the light. The subscript $I C E$ represents a data obtained from a chemical simulation with CHEMKIN using a closed 0-D IC-engine reactor. Finally, the subscript $x$ represents one of the experimental methods, photo-multiplier or high speed camera.

The average of the errors in absolute value $\left(\bar{\varepsilon}=\sum|\varepsilon| / n\right)$, has been calculated for each fuel, as well as its confidence interval with a confidence level of $95 \%$. The following results are obtained:

- Mean relative deviation $(\bar{\varepsilon})$ between simulations and photo-multiplier: [0.531 1.686] \% for $n$-heptane and [1.652 2.930] \% for iso-octane.

- Mean relative deviation $(\bar{\varepsilon})$ between simulations and high speed camera: [0.581 1.725] \% for $n$-heptane and [1.602 2.910] \% for iso-octane.

Of course, the times obtained from the experimental methods should be virtually the same, since both methods measure the same parameter in 
parallel. In fact, the confidence interval with a confidence level of $95 \%$ of the mean relative deviation between these two methods is equal to [0.069 $0.116] \%$ for $n$-heptane and to [0.112 0.223$] \%$ for iso-octane. The existence of certain deviation between both experimental method is justified by the different acquisition frequency.

The chemical kinetic mechanism is able to predict with high accuracy the time at which the $O H^{*}$ is accumulated (high temperature stage of the autoignition process). Figure 7 shows the time evolution of the normalized $O H^{*}$ intensities from the photo-multiplier and from the high speed camera, as well as the normalized $O H^{*}$ molar fraction from CHEMKIN, for a certain case. Both experimental methods show similar $O H^{*}$ profiles. However, the time of life of the $\mathrm{OH}^{*}$ obtained by CHEMKIN is longer than the obtained experimentally. This is caused because the time of life cannot be completely measured, since the luminous intensity is too low as the temperature decreases. Moreover, the intensity of the $O H^{*}$ accumulated during the cool flames cannot be seen in the experimental results. The $O H^{*}$ intensity is directly related with the amount of accumulated $O H^{*}$ and with the thermodynamic conditions in the combustion chamber. The higher the reached temperature and the higher the concentration of $O H^{*}$, the higher its luminous intensity. The combination of low temperature and small concentration of $O H^{*}$ is the reason why cool flames are not detected by the photo-multiplier nor by the camera. It can be seen that a short time of life of the luminous intensity is directly related with the $C O$ continuum light emission. 


\section{Conclusions}

In this work a study of ignition delay time and generalization of autoignition for PRFs in a RCEM by means of natural chemiluminescence has been performed. The trends of the ignition delay, including the NTC behaviour, were analyzed. The validity of the chemical kinetic mechanism used was checked by comparing its predictions directly with the experimental results. Then, the combustion process was studied from a point of view of $\mathrm{OH}^{*}-\mathrm{CO}$ chemiluminescence. The generalization of the auto-ignition (percent of the combustion chamber ignited) was related with the time of ignition. Finally, the luminous intensity was studied, comparing the experimental results from the photo-multiplier and from the high speed camera with the chemical simulations.

The following conclusions can be deducted from this study:

- The chemical kinetic mechanism used in this work can reproduce not only the trends, but also the values of the experimental ignition delays. Not only the ignition delay referred to the maximum pressure rise can be numerically obtained with high accuracy, but also the ignition delay referred to the maximum radiation. The mean relative deviation between simulations and experiments is lower than $2.93 \%$ in all cases. The results show that simulations under-predict the ignition delay for $n$-heptane whereas the over-predict the ignition delay times for iso-octane.

- Cool flames can not be seen by $O H^{*}$ chemiluminescence by keeping constant the gain during all the combustion process because both the 
$O H^{*}$ concentration and the temperature are too low. $O H^{*}$ luminous intensity starts when the $\mathrm{CO}$ starts oxidizing into $\mathrm{CO}_{2}$, since before all the generated $O H^{*}$ is consumed by the generation of $C O$. The maximum intensity appears very close to maximum oxidation rate of the $\mathrm{CO}$ to $\mathrm{CO}_{2}$, which coincides with the time of maximum pressure rise rate. This makes it difficult to separate one from the other by just measuring luminosity. Nevertheless, it has been seen that the time of life of the $O H^{*}$ is much longer than that of the $C O$. So, the time of life is a good indicator that the luminosity seen corresponds to $O H^{*}$.

- The maximum area occupied by natural chemiluminescence is strongly dependent on where ignition occurs. For ignitions far away of TDC, the thermodynamic conditions in the combustion chamber are not optimal for the propagation of the auto-ignition front, leading to slower ignitions and areas below $100 \%$.

- The maximum luminous intensity has a potential behavior with the maximum temperature reached in the cycle, being higher in case of using iso-octane for the same temperature. The higher the initial temperature, the lower the EGR rate or the higher the equivalence ratio, the higher the maximum luminous intensity. However, a higher reactivity of the mixture does not imply a higher combustion intensity. If ignition occurs far away from TDC, the maximum thermodynamic conditions reached can be lower than the ones obtained with a less reactive mixture that ignites near TDC, leading to lower luminous intensity. 


\section{Acknowledgements}

The authors would like to thank different members of the LAV team of the ETH-Zürich for their contribution to this work. The authors are grateful to the Universitat Politècnica de València for financing the Ph.D. Studies of W.Vera-Tudela (FPI SP1 grant 30/05/2012) and his stay at ETH-Zürich (grant 30/12/2014). Finally, the authors would like to thank the Spanish Ministry of Education for financing the Ph.D. Studies of Darío López-Pintor (grant FPU13/02329) and his stay at ETH-Zürich (grant EST14/00626).

\section{Notation}

$B D C \quad$ Bottom Dead Center

$C R \quad$ Compression Ratio

EGR Exhaust Gas Recirculation

$\mathrm{Fr} \quad$ Working equivalence ratio

FWHM Full Width at Half Maximum

HCCI Homogeneous Charge Compression Ignition

ICE Referred to data obtained from CHEMKIN using the internal combustion engine reactor

LTC Low Temperature Combustion

NTC Negative Temperature Coefficient

$P_{i} \quad$ Initial pressure

PCCI Premixed Charge Compression Ignition

PHM Photo-multiplier 


\author{
PRF Primary Reference Fuels \\ RCEM Rapid Compression Expansion Machine \\ SI Spark Ignition \\ $T_{i} \quad$ Initial temperature \\ TDC Top Dead Center \\ $t_{i} \quad$ Ignition delay time \\ UHC Unburned hydrocarbons \\ $Y_{\mathrm{O} 2} \quad$ Oxygen mass fraction \\ $\epsilon \quad$ Percentage deviation in ignition delay referred to the max- \\ imum pressure rise between experimental and simulation \\ results \\ $\bar{\epsilon} \quad$ Mean relative deviation in ignition delay referred to the \\ maximum pressure rise between experimental and simula- \\ tion results \\ $\varepsilon \quad$ Percentage deviation in ignition delay referred to the peak \\ of $O H^{*}$ or maximum oxidation rate of $C O$ between exper- \\ imental and simulation results \\ $\bar{\varepsilon} \quad$ Mean relative deviation in ignition delay referred to the \\ peak of $O H^{*}$ or maximum oxidation rate of $C O$ between \\ experimental and simulation results
}




\section{References}

[1] U. Asad, J. Tjong, and M. Zheng. Exhaust gas recirculation - Zero dimensional modelling and characterization for transient diesel combustion control. Energy Conversion and Management, 86:309-324, 2014.

[2] T. Li, D. Wu, and M. Xu. Thermodynamic analysis of EGR effects on the first and second law efficiencies of a boosted spark-ignited direct-injection gasoline engine. Energy Conversion and Management, 70:130-138, 2013.

[3] Z. Zheng, L. Yue, H. Liu, Y. Zhu, X. Zhong, and M-Yao. Effect of two-stage injection on combustion and emissions under high EGR rate on a diesel engine by fueling blends of diesel/gasoline, diesel/n-butanol, diesel/gasoline/n-butanol and pure diesel. Energy Conversion and Management, 90:1-11, 2015.

[4] S.S. Nathan, J.M. Mallikarjuna, and A. Ramesh. An experimental study of the biogas-diesel HCCI mode of engine operation. Energy Conversion and Management, 51:1347-1353, 2010.

[5] K. Bahlouli, U. Atikol, R.K. Saray, and V. Mohammadi. A reduced mechanism for predicting the ignition timing of a fuel blend of natural-gas and n-heptane in HCCI engine. Energy Conversion and Management, 79:85-96, 2014.

[6] R. Augusta, D.E. Foster, J.B. Ghandhi, J. Eng, and P.M. Najt. Chemiluminescence measurements of homogeneous charge compression ignition (HCCI) combustion. In SAE Technical Papers, editor, 2006 SAE World Congress, Detroit, MI; United States, 3 2006. Code 90162.

[7] H.F. Liu, M.F. Yao, C. Jin, P. Zhang, Z.M. Li, and Z.Q. Zheng. Chemiluminescence spectroscopic analysis of homogeneous charge compression ignition combustion processes. Spectroscopy and Spectral Analysis, 30:2611-2615, 2010. 
[8] E. Mancaruso and B.M. Vaglieco. Optical investigation of the combustion behaviour inside the engine operating in HCCI mode and using alternative diesel fuel. Experimental Thermal and Fluid Science, 34:346-351, 2010.

[9] A. Dubreuil, F. Foucher, and C. Mounaïm-Rousselle. Analysis of flame and $\mathrm{OH}^{*}$ natural emissions of n-heptane combustion in a Homogeneous Charge Compression Ignition (HCCI) engine: Effect of burnt gas dilution. Energy and Fuels, 23:1406-1411, 2009.

[10] H. Liu, Z. Zheng, M. Yao, P. Zhang, Z. Zheng, B. He, and Y. Qi. Influence of temperature and mixture stratification on hcci combustion using chemiluminescence imagenes and cfd analysis. Applied Thermal Engineering, 33-34:135.143, 2012.

[11] H. Anders, M. Christensen, B. Johansson, A. Franke, M. Richter, and M. Aldén. A study of the homogeneus charge compression ignition combustion process by chemiluminescence imaging. SAE Technical Paper, (1999-01-3680), 1999.

[12] C. Jin and Z. Zheng. A review on homogeneus charge compression ignition and low temperature combustion by optical diagnostics. Journal of Chemistry, 2015:23, 2015.

[13] M. Sjoberg and J.E. Dec. An investigation into lowest acceptable combustion temperatures for hydrocarbon fuel in HCCI engines. Proceedings of the Combustion Institute, 30:2719-2726, 2005.

[14] D. Mitakos, C. Blomberg, Y. Wright, P. Obrecht, B. Schneider, and K. Boulouchos. Integration of a cool-flame heat release rate model into a 3-stage ignition model for HCCI applications and different fuels. SAE Paper no. 2014-01-1268, 2014.

[15] G. Barroso, A. Escher, and K. Boulouchos. Experimental and numerical investigations on HCCI combustion. SAE Paper no. 2005-24-038, 2005.

[16] D. Mitakos, C. Blomberg, A. Vandersickel, Y. Wright, B. Schneider, and K. Boulouchos. Ignition delays of different homogeneous fuel-air mixtures in a Rapid Compression Expansion Machine and comparison with a 3-stage-ignition model parametrized on shock tube data. SAE Paper no. 2013-01-2625, 2013. 
[17] S. Schlatter, B. Schneider, Y. Wright, and K. Boulouchos. Comparative study of ignition systems for lean burn gas engines in an optically accessible Rapid Compression Expansion Machine. SAE Paper no. 2013-24-0112, 2013.

[18] T. Steinhilber and T. Sattelmayer. The effect of water addition on HCCI diesel combustion. SAE Paper no. 2006-01-3321, 2006.

[19] S. Schlatter, B. Schneider, Y. Wright, and K. Boulouchos. Experimental study of ignition and combustion characteristics of a diesel pilot spray in a lean premixed methane/air charge using a Rapid Compression Expansion Machine. SAE Paper no. 2012-01-0825, 2012.

[20] A.G. Gaydon. The Spectroscopy of Flames. Chapman and Hall, 1974.

[21] G. Woschni. A universally applicable equation for the instantaneous heat transfer coefficient in the internal combustion engine. SAE Paper no. 670931, 1967.

[22] J. Benajes, P. Olmeda, J. Martín, and R. Carreño. A new methodology for uncertainties characterization in combustion diagnosis and thermodynamic modelling. Applied Thermal Engineering, 71:389-399, 2014.

[23] F. Payri, S. Molina, J. Martín, and O. Armas. Influence of measurement errors and estimated parameters on combustion diagnosis. Applied Thermal Engineering, 26:226-236, 2006.

[24] H.J. Curran, P. Gaffuri, Pitz W.J, and C.K. Westbrook. A comprehensive modeling study of n-heptane oxidation. Combustion and Flame, 114:149-177, 1998.

[25] H.J. Curran, P. Gaffuri, W. J. Pitz, and C. K. Westbrook. A comprehensive modeling study of iso-octane oxidation. Combustion and Flame, 129:253-280, 2002.

[26] H.J. Curran, W.J. Pitz, C.K. Westbrook, C.V. Callahan, and F.L. Dryer. Oxidation of automotive primary reference fuels at elevated pressures. Proceedings of the Combustion Institute, 27:379-387, 1998. 
[27] J. M. Desantes, J. J. López, S. Molina, and D. López-Pintor. Design of synthetic EGR and simulation study of the effect of simplified formulations on the ignition delay of isooctane and n-heptane. Energy Conversion and Management, 96:521-531, 2015. 